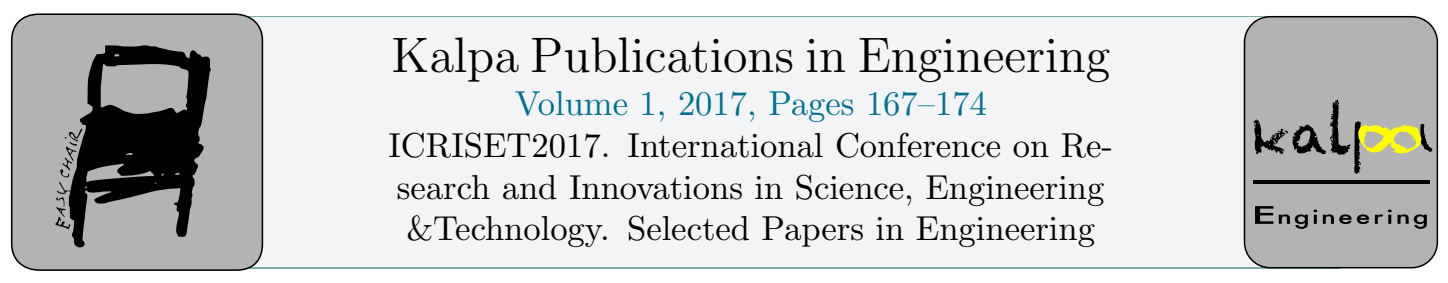

\title{
Analysis of Bolster and Stripper Assembly of High Pressure Molding Machine
}

\author{
Tushar D. Desai \\ Research Scholar: Mechanical Dept. \\ B. V. M. Engineering College
}

Anand, India

\author{
Dr. Vina D. \\ Chauhan \\ Professor: \\ Mechanical \\ Dept. \\ B. V. M \\ Engineering \\ College \\ Anand, India
}

Dhara $P$.

Trivedi

Assistant

Professor:

Mechanical Dept.

B. V. M.

Engineering

College

Anand, India

\begin{abstract}
Bolster and Stripper Assembly is used to support mold box, match plate and pattern for mold preparation with green sand in high pressure molding machine. Different types of molding machines used for preparation of mold from green sand are flask type molding machine and flask less type molding machine. Commonly used molding machine is flask type molding machine with bolster and stripper assembly for mold preparation.

This paper explains design and analysis of bolster and stripper assembly for manufacturing required size mold in high pressure green sand molding machine
\end{abstract}

Keywords—Bolster; stripper; squeeze pressure;mold box;green sand

\section{INTRODUCTION}

The most common method used to create metal castings is green sand molding. In this process, granular refractory sand is coated with a mixture of bentonite clay, water and in some cases binder or additives are used. The binders used for harden and hold the mold shape to withstand against high pressure of the molten metal during pouring process of molten metal. The green sand mixture is most commonly compacted by hand or through mechanical force by using some mechanism around a pattern to create a mold. The mechanical force can be compacted by slinging, jolting, squeezing or by impact/impulse. Points should be taken into consideration for the green sand molding processes are as follow:

- For many metal forming applications, i.e. casting, green sand molding processes are the most cost-effective and given high productivity of all metal forming operations; 
- Green sand processes readily used for automated systems for high-volume work as well as short runs and prototype work;

- In the case of slinging, hand or manual jolt or squeeze molding to form the mold, wood or plastic pattern materials can be used. High-pressure, high-density molding methods almost always require metal pattern equipment, because in wood pattern or plastic pattern due to high pressure, damage takes place of pattern

- high-pressure and high-density molding produces by high pressure molding machine manufacturing a well-compacted mold, which gives better surface finish, casting dimensions are very accurate or in given tolerances;

- Properties of green sand are adjustable within wide range, so it is possible to use this process with all types of green sand molding equipment.

- Design of the molding machine is carried out on the basis of molds required to produce per unit time. For industrial use there is a high demand or high production rate is required. So, capacity of the molding machine is also high.

- From the size of the mold box and squeezing pressure in high pressure molding machine, dimension, materials etc. of the bolster and stripper and others parts of the machine are decided

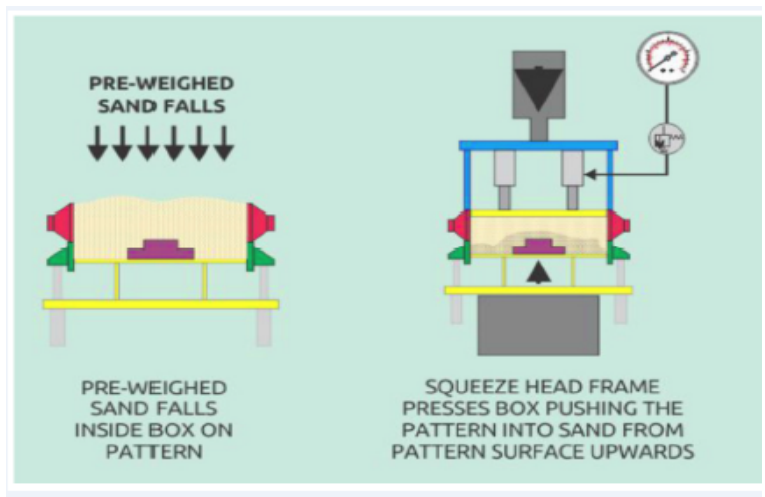

Figure 1: Stage 1: Working principle of molding machine

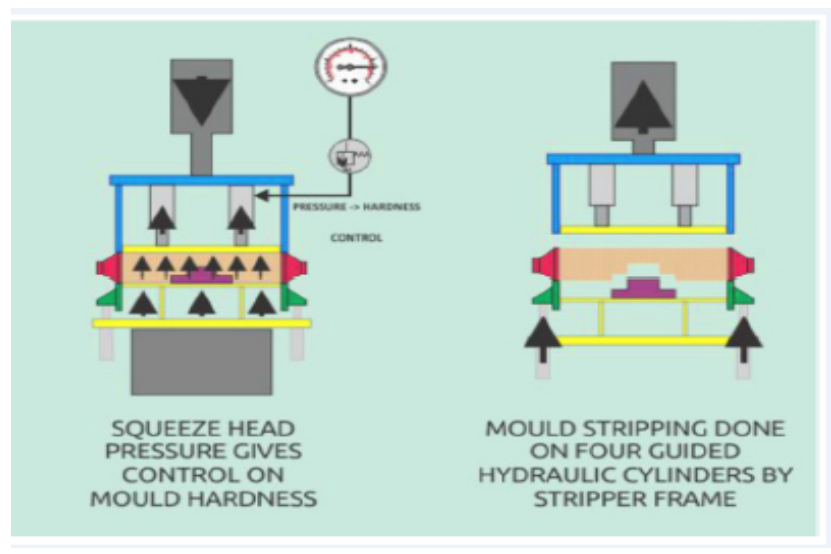

Figure 2: Stage 2: Working principle of molding machine 
A. High pressure molding machine

To make a mold, it is provide better surface finish to mold with a hydraulic squeeze. The hydraulic squeeze provides a uniform mold hardness for all of the surfaces and also around the edges of the flask.

The operational settings for the Hydraulic Squeeze are adjustable through the operator interface. The cope and drag molding operations can have different molding parameters. This machine can be used with different types of pattern like wooden, aluminum etc.

\section{B. Bolster and Stripper assembly}

Bolster and Stripper assembly is design to support patterns during operation and eject mold after process is over without distortion. There are vents all around the bolster to venting air during squeezing pressure for molding process. Stripper is assembled with bolster by using some mechanism like hydraulic cylinder or spring damper system to guide mold and form an important assembly for producing accurate mold and so casting.

The mold box is located on pins which are already attach with the stripper for easy locating and guiding of mold box. Match plate with pattern is supported by bolster with the help of pattern support. Combined tolerance of stripper pin with match plate is required to achieve for accuracy of casting.

\section{Components of bolster and stripper assembly}

$>$ Stripper: It provides support for the mold box during operation.

$>$ Liner Plate of Stripper: Liner plates avoid the damage of stripper due to friction between bolster and stripper during operation.

> Stripper Pad: Pad is use in stripper for proper resting of the stripper on the bolster pad during squeeze operation.

D Bolster: It provides support for the pattern support and match plate and it is also resting on the turn table for rotation of the Cope and Drag pattern during molding operation.

$>$ Pattern Support: Pattern support is fitted in the bolster housing for support of the pattern during squeezing operation.

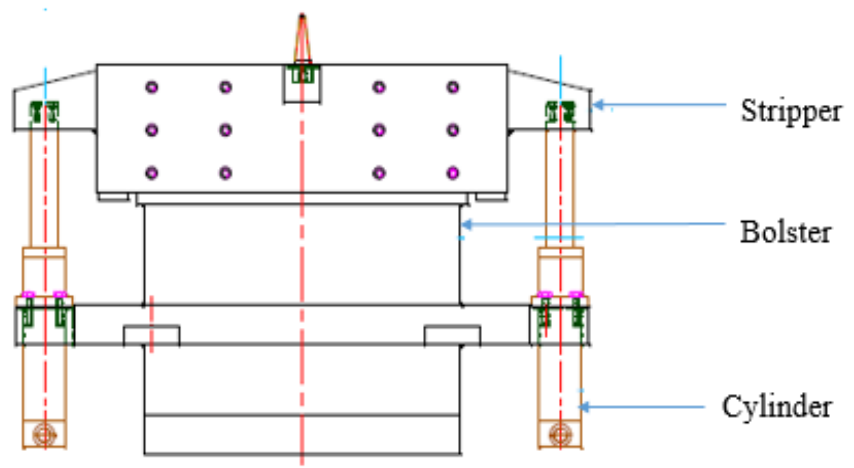

Figure 3: Schematic diagram of bolster and stripper assembly

Bolster Liner Plate: it avoid the damage of the bolster material due to relative motion between bolster and stripper during operation.

$>$ Bolster Pad: For the support of stripper during entire operation 
Match Plate: It is used for matching of cope and drag patterns after the whole operation is completed. Cope and Drag are resting on the match plate during operation.

\section{LITERATURE REVIEW}

In 2012, Li Hua [1], in this paper, high squeeze pressure is applied for molding process in modern molding machine. Because unique characteristics of molding sand and nonlinear property of squeezing pressure.so in this process both sand grain property and nonlinearity of squeezing pressure are considered.in this paper, for constitutive relation they considered mechanical property like stiffness during squeezing pressure and volumetric deformation due to static pressure.in this paper, they compared the result of simulation model and experimental model of the mold with pattern.

In 2014, BySuvanjan Bhattacharyya[2]; In this paper, they used kunkel wagner technology for producing mold in high pressure molding machine.By using this technology one can meet high demand of product within given time. This technology is widely used in india for meeting higher production demand within short time period. This paper provide information for produce mold by using flask type mold process to reduce inventory and for that use of high pressure molding machine with help of bolster and stripper assembly for holding mold box during operation.

In 2014, Raghwendra Banchhor[3];Inthis paper, the versatility of molding processes available and demonstrated all molding process for the metal forming process. Due to high flexibility, advantage and benefits match with the proper product application. This paper summarize process capability, advantages and limitation by comparing conventional process and modern molding processes.so basic objective of this paper was to compare the different types of molding process and evaluate the results. This paper conclude that green sand molding processes are the most cost effective metal forming process. This process readily leads themselves for high volume work as well as for prototype work.

It is concluded from the literature review,

> Green sand mold processes are the most cost-effective of all metal forming operations; these processes readily used for automated systems for high-volume work as well as short runs and prototype work.

> Authors have compared results of simulation model and experiments during squeezing operation and conclude requirements of size of bolster and stripper other components.

> Authors have compared different types of molding process like injection molding, flask less type molding machine, flask type molding machine etc. and concluded advantages used of flask in molding machine.

\section{DETAILED DESIGN}

Assumptions are taken for Box size and other dimensions of the bolster and stripper assembly for the high pressure molding machine for design of assembly are as follow:

As per box size and given squeezing pressure in high pressure molding machine, dimensions of the bolster and stripper and other components of the assembly can be obtain.

Given data:

Box size $=950 \times 850 \times 150 \mathrm{~mm}^{3}$

Squeezing pressure of machine $=1 \mathrm{~N} / \mathrm{mm}^{2}$

Weight of mold $=15 \mathrm{~kg}$ per cycle 
Weight of pattern: As per machine specification

Weight of pattern support $=50 \mathrm{~kg}$ Approx.

Total load applied on assembly,

Total load $=$ load due to squeeze pressure + weight of mold + weight of pattern support

$$
=150 \mathrm{kN}
$$

Thickness of a wall of bolster and stripper:

As per squeezing pressure applied on sand mold by a piston plate assembly, load is transmitted to the stripper uniformly throughout box of the stripper.

So, stripper material goes under deformation due to the Uniformly Distributed Load in the mold box

Deflection: $=\frac{W L^{4}}{384 E I},($ Both ends are fixed $)$

Where, $\mathrm{I}=\frac{\mathrm{wt}^{3}}{12}$

Thickness of Match Plate:

$$
\begin{aligned}
\mathrm{t}=\mathrm{abk} \sqrt{\frac{p}{\sigma\left(a^{2}+b^{2}\right)}} \\
\text { Where, } \\
\bullet \mathrm{t}=\text { thickness of a plate, } \\
\bullet \mathrm{a}=\text { length of a plate, } \\
\bullet \mathrm{b}=\text { width of a plate, } \\
\bullet \mathrm{p}=\text { Squeezing pressure in } \mathrm{N} / \mathrm{mm}^{2}, \\
\bullet \sigma=\text { Allowable design stress, } \\
\bullet \mathrm{k}=\text { coefficient depends upon joining material }
\end{aligned}
$$

\section{A. Bolster and Stripper assembly}

Table 1: Dimensions of Bolster and stripper assembly

\begin{tabular}{|c|c|c|c|}
\hline $\begin{array}{c}\text { Name of the } \\
\text { Components }\end{array}$ & $\begin{array}{c}\text { Size } \\
(\text { Length } \times \text { Width })\end{array}$ & Height & Thickness \\
\hline Mold Box & $950 \times 850 \mathrm{~mm}^{2}$ & $150 \mathrm{~mm}$ & $10 \mathrm{~mm}$ \\
\hline Stripper & $918 \times 818 \mathrm{~mm}^{2}$ & $195 \mathrm{~mm}$ & $50 \mathrm{~mm}$ \\
\hline Bolster & $760 \times 664 \mathrm{~mm}^{2}$ & $410 \mathrm{~mm}$ & $25 \mathrm{~mm}$ \\
\hline $\begin{array}{c}\text { Stripper Liner } \\
\text { Liner 1 }\end{array}$ & $790 \times 195 \mathrm{~mm}^{2}$ & - & $10 \mathrm{~mm}$ \\
Liner 2 & $718 \times 195 \mathrm{~mm}^{2}$ & - & $10 \mathrm{~mm}$ \\
\hline $\begin{array}{c}\text { Bolster Liner } \\
\text { Liner 1 }\end{array}$ & $798 \times 25 \mathrm{~mm}^{2}$ & - & $24 \mathrm{~mm}$ \\
Liner 2 & $650 \times 25 \mathrm{~mm}^{2}$ & - & $24 \mathrm{~mm}$ \\
\hline Match Plate & $750 \times 650 \mathrm{~mm}^{2}$ & - & $30 \mathrm{~mm}$ \\
\hline Pattern Support & $646 \times 546 \mathrm{~mm}^{2}$ & $410 \mathrm{~mm}$ & $10 \mathrm{~mm}$ \\
\hline
\end{tabular}

IV. ANALYSIS OF BOLSTER AND STRIPPER

Analysis of bolster and stripper is carried out on the basis of squeezing pressure applied during molding process in high pressure green sand molding machine. 
- Due to squeezing pressure stresses and deformation generated in bolster and stripper.

- For the analysis of components of bolster and stripper assembly in ANSYS boundary conditions for both bolster and stripper are carried out as given below:

- Boundary conditions for Bolster : Squeezing pressure

\section{Fixed support}

- Boundary conditions for stripper: Squeezing pressure Sliding support

A. Stress and Deformation in bolster
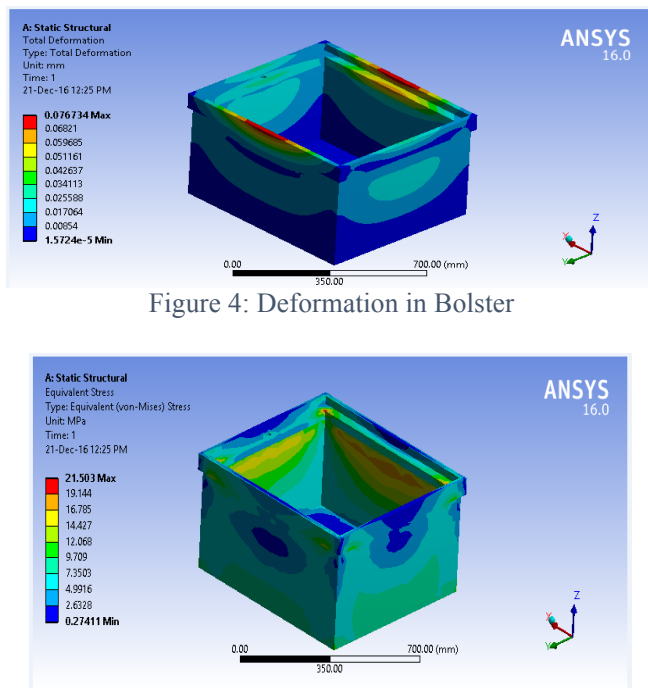

Figure 5: Stresses in Bolster

B. Stress and Deformation in stripper

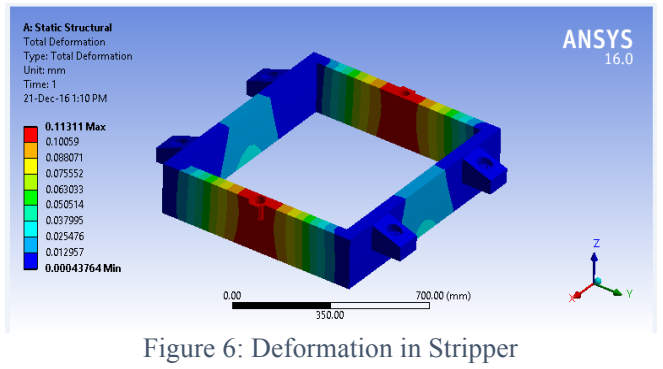




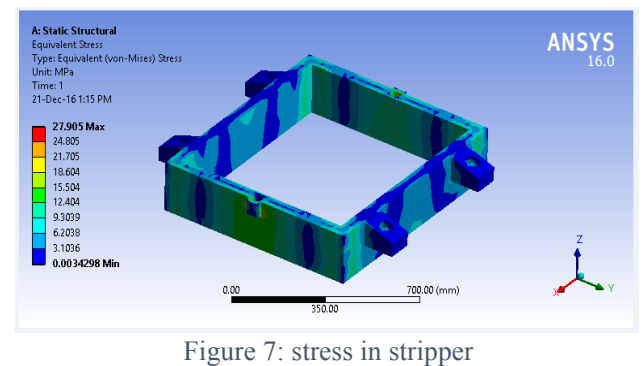

C. Analysis results of bolster and stripper

Von misses stress generate in the bolster $=22 \mathrm{Mpa}$

Deformation bolster plate $=0.08 \mathrm{~mm}$

Von misses stress generate in stripper $=28 \mathrm{Mpa}$

Deformation in stripper $=0.1 \mathrm{~mm}$

So, allowable stress of the material of bolster and stripper assembly $350 \mathrm{Mpa}$ which is far away of stress generate in bolster and stripper assembly due to loading applied during operation.

Maximum allowable deformation in the mold is nearly $0.5 \mathrm{~mm}$ because for more deformation, distortion of mold takes place.

\section{CONCLUSION}

It is concluded that compare to the other mold making process like injection molding process design and manufacturing of die is high and in high pressure molding machine pattern changes take less time and design of the components is also easy so, in flask type molding machine, bolster and stripper assembly is use for support flask, easy removal and change of pattern and easy to eject mold at the end of operation without distortion of mold.

From analysis of design of bolster and stripper assembly it is concluded that stress calculated using different design criteria and stress and deformation generated in components of assembly are within the limit of given allowable stress of materials.

\section{REFERENCES}

[1] Li Hua , Wu Junjiao , Huang Tianyou and Makino Hiroyasu, A new numerical simulation model for high pressure squeezing molding Machine, (IJAERS), volume 8, issue 2, Feb-2011.

[2] Suvanjan Bhattacharyya 1, Debdeep Chatterjee 2, Srijan Paul 2, Sumanta Laha 2, Preetam Das 2, Diptajit Sadhukhan 2, Automatic Molding plant based on Kunkel Wagner Technology(IJAREST), issue 3, March 2014.

[3] Raghwendra Banchhor, S.K.Ganguly, International Journal of Recent Development in Engineering and Technology, Critical Assessment of Green Sand Molding Processe,(IJRDET),ISSN 2347 - 6435 (Online) Volume 2, Issue 4, April 2014.

[4] Maeda Y, Maruoka Y, Makino H and Nomura H. Squeezing Molding Simulation Using Distinct Element Method Considering Green Sand Properties. In: Proc. Research and Development in Net Shape Manufacturing International Conference.

Birmingham, UK: 2001.

[5] William Orthowein, Machine Component Design, JAICO Publishing house .

[6] V.B.Bhandari, Introduction to Machine Design , Tata Macgraw Hill Education Pvt. Ltd.-2001

[7] Pandya And Shah, Machine Design Charotar Publication House, thirteenth edition

[8] R.S.Khurmi And J.K.Gupta, A textbook of Machine Design, S.Chand.

[9] S K Duggal, Design of steel Structures, Tata Macgraw Hill Education Pvt. Ltd., Third edition-2009 
[10] B.S.Raghuwanshi, Workshop Technology Vol. 1, Dhanpatrai \& Co.Tenth Edition

[11] Richard G.Budynas And J.Keith Nisbett, Shigley's Mechanical Engineering Design, Tata Macgraw Hill Education Pvt. Ltd.Ninth Edition 